\title{
Sibling competition does not magnify inbreeding depression in North American Arabidopsis lyrata
}

\author{
Yan $\mathrm{Li} \mathbb{D}^{1} \cdot$ Mark van Kleunen (D) $^{1,2} \cdot$ Marc Stift $^{1}$
}

Received: 5 April 2019 / Revised: 13 August 2019 / Accepted: 13 August 2019 / Published online: 20 September 2019

(c) The Author(s), under exclusive licence to The Genetics Society 2019

\begin{abstract}
About half of all angiosperms have some form of molecular self-incompatibility to promote outcrossing. If selfincompatibility breaks down, inbreeding depression $(\delta)$ is the main barrier to the evolution of self-fertilisation (selfing). If inbreeding depression is lower than $50 \%(\delta<0.5)$, the inherent transmission advantage of selfers should theoretically drive the evolution of selfing. However, this does not always happen in practice. For example, despite frequent breakdowns of self-incompatibility in North American Arabidopsis lyrata, selfing has only evolved in few populations. This is surprising given that previous inbreeding-depression estimates were well below the 0.5 threshold. Here, we test whether this could be due to underestimation of true inbreeding depression in competition-free environments. Specifically, we tested whether direct competition between crossed and selfed siblings magnified inbreeding-depression estimates in $A$. lyrata. We found that this was neither the case for belowground nor for aboveground biomass. For reproductive traits, there was hardly any significant inbreeding depression regardless of competition. Combined with previous findings that drought stress and inducing defence also did not magnify inbreeding depression, our results suggest that the relatively low estimates of inbreeding depression for biomass are indeed realistic estimates of the true inbreeding depression in North American $A$. lyrata.
\end{abstract}

\section{Introduction}

Evolutionary transitions to self-fertilisation (selfing) from self-incompatible ancestors are frequent in plants (Barrett 2002; Charlesworth 2006; Igic et al. 2008; Shimizu and Tsuchimatsu 2015). The first step in such transitions is the breakdown of self-incompatibility, rendering individuals self-compatible. In species with a genetically controlled self-incompatibility system, self-compatible individuals tend to occur at low frequency in some populations,

Supplementary information The online version of this article (https:// doi.org/10.1038/s41437-019-0268-1) contains supplementary material, which is available to authorized users.

Yan Li

yan.li@uni-konstanz.de

1 Ecology, Department of Biology, University of Konstanz, Universitätsstrasse 10, D-78457 Konstanz, Germany

2 Zhejiang Provincial Key Laboratory of Plant Evolutionary Ecology and Conservation, Taizhou University, 318000 Taizhou, China suggesting that the breakdown of self-incompatibility is not exceptional (e.g., Tsukamoto et al. 2003, Busch et al. 2010, Foxe et al. 2010). However, although individuals with high selfing rates theoretically have an immediate transmission advantage over obligately outcrossing (self-incompatible) individuals (Fisher 1941; Stone et al. 2014), the breakdown of self-incompatibility only rarely leads to shifts to higher selfing rates at the population level (e.g., Foxe et al. 2010; Mable et al. 2017).

It is generally thought that this is because selfed-progeny tend to have reduced fitness relative to outcrossed progeny. Such inbreeding depression is expected because of the increased homozygosity associated with selfing (Wright et al. 2013), which leads to increased expression of recessive deleterious alleles in selfers (Charlesworth and Willis 2009). Classical models predict that inbreeding depression of more than $50 \%$ (i.e., a more than $50 \%$ reduction in fitness of selfed- relative to crossed-progeny) should cancel out the transmission advantage of selfers and prevent the evolution of selfing (Kondrashov 1985; Lande and Schemske 1985; Porcher and Lande 2005), although selfing could evolve with much higher levels of inbreeding depression under conditions where reproductive assurance is important 
(reviewed by Busch and Delph 2012). On the other hand, inbreeding depression of less than $50 \%$ should not be sufficient to negate the transmission advantage of selfers, and should thus not prevent the evolution of selfing (Porcher and Lande 2005; Busch and Delph 2012). The magnitude of inbreeding depression therefore plays a key role in determining how prone outcrossing populations are to evolve higher selfing rates.

In line with theory (e.g., Charlesworth and Charlesworth 1987), self-incompatible species tend to suffer significant inbreeding depression $(\delta>0)$, but there is considerable variation both among and within species (reviewed in Sletvold et al. 2013, also see Bellanger et al. 2015; Carleial et al. 2017). Estimates across species ranged from $\delta=0.23$ in Phlox drummondii (Levin 1984; Levin and BulinskaRadomska 1988) to the theoretical maximum of $\delta=1$ in Campanula rapunculoides (Vogler et al. 2001). Inbreedingdepression estimates $(0.30<\delta<0.35)$ for North American Arabidopsis lyrata outcrossing populations were relatively low compared with European populations (Sletvold et al. 2013). This has been invoked as an explanation for why the breakdown of self-incompatibility could lead to the evolution of high selfing rates in some of the North American populations (Carleial et al. 2017). However, it remains unclear why selfing does not always evolve in cases where inbreeding depression is well below the $\delta=0.5$ threshold.

A potential explanation for this may be that previous experimental setups have underestimated the true level of inbreeding depression, because they have excluded competitive interactions. Particularly intraspecific competition is a major factor driving population dynamics (Schoener 1973), which often even outweighs the effects of interspecific competition (Connell 1983; de Villemereuil and Lopez-Sepulcre 2011). Direct competition between crossed and selfed siblings is expected to magnify inbreeding depression, because stronger individuals are likely to suppress the weaker ones (Agrawal and Whitlock 2010). One would expect this effect to be most important in species that lack adaptations to facilitate seed dispersal, and that produce relatively large numbers of seeds. In several species meeting these criteria, inbreeding depression was stronger when juvenile plants derived from cross- and self-fertilisation were forced to compete directly: the grasses Agrostis tenuis and Anthoxanthum odoratum (Antonovics 1968); and the forbs Mimulus guttatus (Carr and Dudash 1995), Plantago coronopus (Koelewijn 2004) and Hibiscus trionum (Lhamo et al. 2006). Although a mini-review based on 20 species suggested that the pattern is far from universal (Appendix 1 in Willi et al. 2007), broader support comes from plant species that have seeds with adaptations to disperse (e.g., Crepis sancta, Cheptou et al. 2001). This underscores the importance of considering competitive interactions during juvenile plant growth in studies of inbreeding depression.
In this study, we performed a greenhouse experiment to assess the performance and estimate inbreeding depression for plants from outcrossing and selfing populations of $A$. lyrata subsp. lyrata. This is of particular interest to understand why selfing has only evolved in some populations, despite the presence of some self-compatible individuals in most populations (Foxe et al. 2010). Given that seeds do not have any adaptations to promote dispersal, A. lyrata is a species where one would expect intensive competition between siblings. However, this has not been taken into account in previous studies of inbreeding depression. Therefore, we assessed inbreeding depression both with and without direct competitive interactions between selfed and crossed siblings that were planted as seedlings. We used both below- and above-ground biomass as proxies of performance. Specifically, we addressed the following questions: (1) Does sibling competition magnify inbreeding depression? (2) Are there differences between mating systems in performance and inbreeding depression, and are the patterns similar for below- and above-ground biomass?

\section{Materials and methods}

\section{Study species and seed material}

A. lyrata subsp. lyrata is a member of the mustard family (Brassicaceae), and occurs on sandy and rocky shores and serpentine soils. It is usually self-incompatible and outcrossing, but some populations in the Great Lakes region of North America have become self-compatible and undergone a transition to selfing (Mable et al. 2005; Mable and Adam 2007; Foxe et al. 2010). To estimate inbreeding depression by measuring the performance of selfed- relative to crossedprogeny (Ågren and Schemske 1993), we used a previously described seed collection (Carleial et al. 2017) of crossedand selfed-progeny from multiple mother plants. For all mother plants, crossed-progeny had been produced by siring mother plants with pollen from a haphazardly chosen plant from the same population. For mother plants from outcrossing populations, to by-pass self-incompatibility, selfed-progeny had been obtained by placing self-pollinated plants in $\mathrm{CO}_{2}$-enriched air (Nakanishii et al. 1969). For mother plants from selfing populations, although these can self-fertilise without special treatment, selfed-progeny had been produced in the same way (in $\mathrm{CO}_{2}$-enriched air). In addition, to test for potential side effects of $\mathrm{CO}_{2}$-enrichment, selfed-progeny had also been produced under ambient conditions, which was obviously only possible for plants from selfing populations. Our experiment included 107 seed families from six outcrossing populations $\left(53 \mathrm{CO}_{2}\right.$-selfed and 54 crossed, from 7 to 10 mother plants per population) and 123 seed families from six selfing populations $\left(36 \mathrm{CO}_{2}-\right.$ 
Fig. 1 Experimental design. Crossed- and selfed plants from six outcrossing and six selfing populations of A. lyrata were grown alone (no competition) or in competition with each other (competition). All crossed plants were raised from seeds produced by cross-pollination under ambient conditions (cross), and selfed plants were raised from seeds produced by selfpollination under $\mathrm{CO}_{2}$-enriched environment (self $\left[\mathrm{CO}_{2}\right]$ ) or under ambient conditions (self [amb]). Actual sample sizes are indicated below each pot.

Numbers in brackets indicate the planned sample size based on seed availability, which was not achieved, mainly because not all seeds germinated

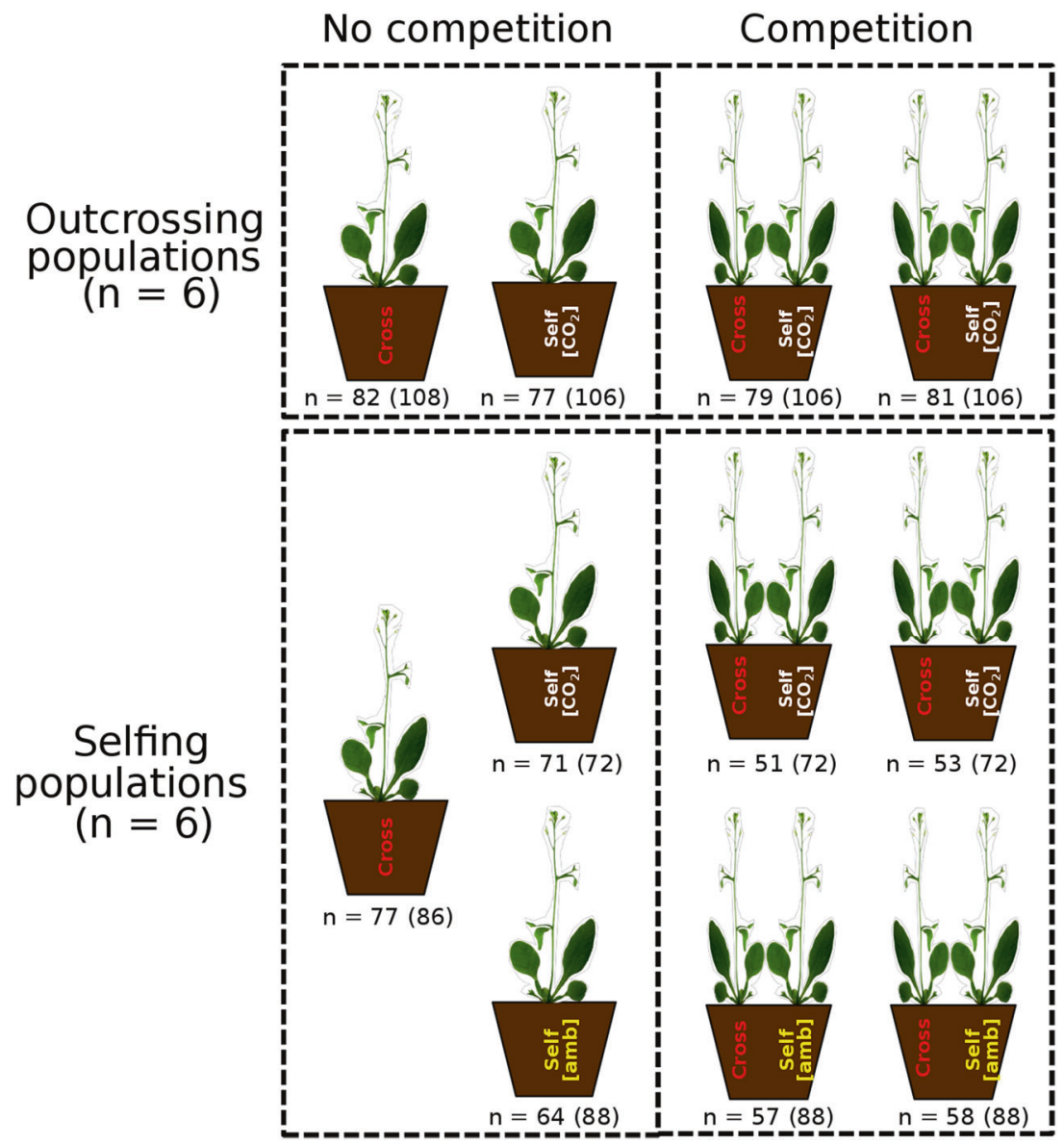

from the same mother (resulting in two pots with two siblings with different cross types: cross vs. self), two served as competitor for a focal plant of the opposite cross type from the same mother (Fig. 1). For selfing populations, to confirm previous findings that $\mathrm{CO}_{2}$ during pollination does not affect growth of progeny (Carleial et al. 2017), our experiment also included selfed seedlings from seed families produced under ambient conditions. These were planted in the same way as the $\mathrm{CO}_{2}$-self progeny (Fig. 1). For some seed families, insufficient seeds germinated, so that the final experiment included 750 of the originally planned 992 pots (see Fig. 1 for details). Pots were randomly assigned to positions on four greenhouse benches in the botanical garden of the University of Konstanz (temperature between 16 and $18{ }^{\circ} \mathrm{C}$ and with no additional lighting), watered ad libitum and fertilised once per week with $0.1 \%(\mathrm{w} / \mathrm{v})$ Scotts Universol ${ }^{\circledR}$ Blue solution (Everris International B. V., Waardenburg, Netherlands).

\section{Measurements}

To test whether selfed and outcrossed plants differ in belowground (root) biomass production, we separately harvested the below- and above-ground biomass of the first plants to compete with a seedling of the opposite cross type 
set of replicate plants (375 pots) four weeks after transplanting, when the roots of the competitors could still be separated. For each plant, we first cut off the aboveground tissue at the substrate surface and placed it in a paper bag. We then washed and cleaned the belowground tissue before putting it in a separate paper bag. The plant samples were dried at $70{ }^{\circ} \mathrm{C}$ for at least 3 days in an oven with ventilation. We then determined the biomass to the nearest microgram for belowground plant parts and to the nearest $0.1 \mathrm{mg}$ for aboveground plant parts.

To test whether selfed and outcrossed plants differed in further development and reproductive traits, the remaining pots were kept for another 7 weeks. On 2 July 2015 (11 weeks after transplanting), we performed the final harvest of the experiment. We scored for each plant whether it had reached the bolting stage (i.e., whether it had started to form an inflorescence). To quantify the investment in sexual reproduction (reproductive potential), we counted the number of flowers (including open flowers and spent flowers, but not flower buds). To allow assessing vegetative and inflorescence biomass, we separately collected the rosette leaves and the inflorescences. The plant parts were dried at $70{ }^{\circ} \mathrm{C}$ for at least 3 days, and weighed to the nearest $0.1 \mathrm{mg}$ to estimate reproductive biomass. As the roots of the competing plants could not be separated (the fine, fragile roots were completely intertwined at this stage), we did not harvest the belowground biomass.

\section{Statistical analyses}

Our procedural control indicated that $\mathrm{CO}_{2}$-enrichment did not have side effects on any of our measures of plant performance (no significant difference between $\mathrm{CO}_{2}$-selfed and ambient-selfed progeny for any of the traits, Table S2). Therefore, we pooled selfed-progeny produced under ambient and $\mathrm{CO}_{2}$-enriched conditions for further analyses. To assess whether sibling competition magnified inbreeding depression, whether there were differences between mating systems in performance and inbreeding depression, we used generalised linear mixed effects models in R 3.4.3 (R Core Team 2017) using the lmer and glmer functions as implemented in the package 'Ime4' (Bates et al. 2015). For belowground biomass, aboveground biomass and inflorescence biomass, the models had a Gaussian error distribution. To improve normality and homogeneity of the residuals, we square-root transformed biomass data prior to analysis. For bolting and the number of flowers, models had a binomial error term and a negative binomial error term, respectively (we used the bobyqa optimiser with a maximum of 10,000 iterations to fit these models). For all models, the fixed effects included mating system (outcrossing vs. selfing), cross type (self vs. cross), competition (with vs. without) and all two- and three-way interactions.
These interactions specifically tested whether inbreeding depression differs between mating systems and is affected by competition. To account for non-independence of plants from the same population and for non-independence of plants from the same mother plant, all models included population (nested in mating system) and mother plant (nested within population) as random effects.

Significant effects of cross type (as a main effect or an interaction) indicate significant inbreeding depression. To facilitate interpretation of the actual magnitudes of inbreeding depression, we calculated inbreeding depression coefficients $(\delta)$ for the four factorial combinations of mating system $\times$ competition for each trait for each population separately. These coefficients were calculated using the following formula: $\delta=\left(\mathrm{W}_{\text {out }}-\mathrm{W}_{\text {self }}\right) / \max \left(\mathrm{W}_{\text {out }}, \mathrm{W}_{\text {self }}\right)$, in which $\mathrm{W}_{\text {out }}$ and $\mathrm{W}_{\text {self }}$ are the mean fitness estimates for crossed- and selfedprogeny, respectively (Ågren and Schemske 1993).

\section{Results}

\section{Plant vegetative performance}

Plants resulting from self-fertilisation (i.e., selfed plants, including $\mathrm{CO}_{2}$-self and ambient-self) produced significantly less biomass than their siblings resulting from crossfertilisation (i.e., crossed plants) (significant effect of cross type for all biomass traits; Table 1). In other words, there was significant inbreeding depression for growth. The inbreeding depression was similar in magnitude for belowground biomass ( $\delta=0.12$ for plants grown alone) and aboveground biomass ( $\delta=0.11$ for plants grown alone) of 4-week old plants (an analysis of total biomass produced very similar results and is presented in Table S3, Fig S1) and for aboveground biomass $(\delta=0.08$ for plants grown alone) of 11-week old plants (Fig. 2).

Inbreeding depression did not differ between outcrossing and selfing populations (no significant interactions between cross type and mating system, Table 1). Outcrossing and selfing populations produced similar amounts of biomass (no significant effect of mating system in Table 1 for all biomass traits). Competition between siblings caused a significant reduction in biomass (significant effect of competition; Table 1; Fig. 2). However, competition did not increase the magnitude of inbreeding depression (no significant interaction between cross type and competition, Table 1; Fig. 2).

\section{Plant reproductive potential}

At the time of harvest, 244 out of 359 experimental plants had reached the bolting stage (i.e., they had started to form an inflorescence). There was significant 
Table 1 Linear mixed model analysis to test for inbreeding depression for vegetative performance for six outcrossing and six selfing populations of A. lyrata

\begin{tabular}{|c|c|c|c|c|c|c|c|c|c|c|}
\hline \multirow{3}{*}{$\begin{array}{l}\text { Explanatory variables } \\
\text { (fixed and random effects) }\end{array}$} & \multirow[t]{3}{*}{$\mathrm{df}_{\text {num }}$} & \multicolumn{6}{|c|}{ 4-week old plants } & \multirow{2}{*}{\multicolumn{3}{|c|}{$\begin{array}{l}\text { 11-week old plants } \\
\text { Aboveground biomass } \\
\text { (Gaussian, square root, } \\
n=359 \text { ) }\end{array}$}} \\
\hline & & \multicolumn{3}{|c|}{$\begin{array}{l}\text { Belowground biomass } \\
\text { (Gaussian, square root, } \\
n=347 \text { ) }\end{array}$} & \multicolumn{3}{|c|}{$\begin{array}{l}\text { Aboveground biomass } \\
\text { (Gaussian, square root, } \\
n=350 \text { ) }\end{array}$} & & & \\
\hline & & ${ }^{\mathrm{a}} \mathrm{df}_{\mathrm{den}}$ & $F$ & $P$ & ${ }^{\mathrm{a}} \mathrm{df}_{\mathrm{den}}$ & $F$ & $P$ & ${ }^{\mathrm{a}} \mathrm{df}_{\mathrm{den}}$ & $F$ & $\mathrm{P}$ \\
\hline \multicolumn{11}{|l|}{ Fixed } \\
\hline Cross type (CT) & 1 & 285.4 & 12.5 & $<0.001$ & 284.4 & 22.6 & $<0.001$ & 298.1 & 12.3 & 0.001 \\
\hline Mating system (MS) & 1 & 11.2 & 0.59 & 0.46 & 10.7 & 0.23 & 0.64 & 14.2 & $<0.001$ & 0.99 \\
\hline Competition (C) & 1 & 274.7 & 20.1 & $<0.001$ & 274.3 & 3.73 & 0.055 & 298.7 & 183.0 & $<0.001$ \\
\hline CT: MS & 1 & 285.4 & 0.05 & 0.82 & 284.4 & 1.71 & 0.19 & 298.1 & 2.36 & 0.13 \\
\hline CT: C & 1 & 282.6 & 0.86 & 0.36 & 282.1 & 2.13 & 0.15 & 297.1 & 0.042 & 0.84 \\
\hline MS: C & 1 & 274.7 & 1.74 & 0.19 & 274.3 & 0.52 & 0.47 & 298.7 & 0.027 & 0.87 \\
\hline CT:MS:C & 1 & 282.6 & $<0.001$ & 0.99 & 282.1 & 0.17 & 0.68 & 297.1 & 0.14 & 0.71 \\
\hline Random & & \multicolumn{3}{|c|}{ SD } & \multicolumn{3}{|c|}{ SD } & \multicolumn{3}{|c|}{ SD } \\
\hline Population & 1 & \multicolumn{3}{|c|}{0.186} & \multicolumn{3}{|c|}{0.025} & \multicolumn{3}{|c|}{0.149} \\
\hline Mother & 1 & \multicolumn{3}{|c|}{0.307} & \multicolumn{3}{|c|}{0.033} & \multicolumn{3}{|c|}{0.159} \\
\hline \multirow[t]{2}{*}{ Residual } & & \multicolumn{3}{|c|}{0.678} & \multicolumn{3}{|c|}{0.065} & \multicolumn{3}{|c|}{0.591} \\
\hline & & \multicolumn{3}{|c|}{$\mathrm{df}_{\mathrm{res}}=336$} & \multicolumn{3}{|c|}{$\mathrm{df}_{\mathrm{res}}=339$} & \multicolumn{3}{|c|}{$\mathrm{df}_{\mathrm{res}}=348$} \\
\hline
\end{tabular}

Cross type represents inbreeding depression in the model (alone or in interaction with competition and/or mating system). Proxies for vegetative performance were belowground biomass and aboveground biomass in 4-week old plants, and aboveground biomass in 11-week old plants. The model error distribution, any applied transformations and sample sizes are indicated in brackets for each trait. For all traits, the model fixed part included cross type (self vs. cross), mating system (outcrossing vs. selfing) and competition (with vs. without), and all two-way and three-way interactions. The random effects included population (nested in mating system) and mother plant (nested in population). Significant values are marked in bold. Significant effects of cross type (as main effect or in interaction) indicate significant inbreeding depression

$d f_{\text {num }}$ : numerator degrees of freedom, $d f_{\text {den }}:$ denominator degrees of freedom

a'Significance tests are based on Satterthwaite's method to adjust $\mathrm{df}_{\mathrm{den}}$, as implemented in the anova command in the package lmerTest (v3.1-0)
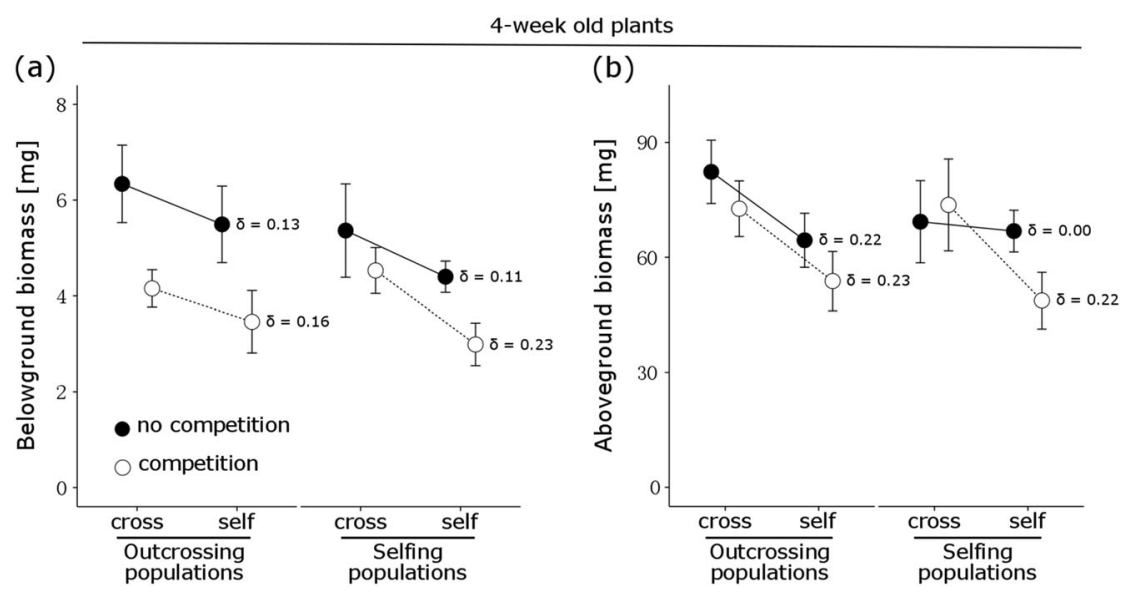

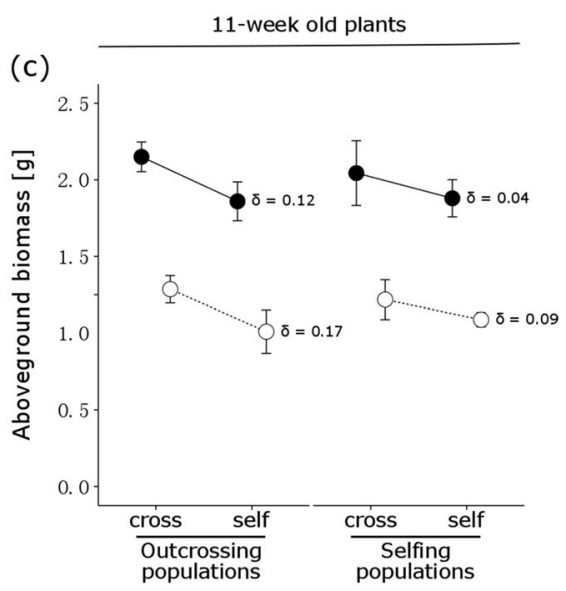

Fig. 2 Vegetative performance of crossed- and selfed-progeny grown alone (no competition) or in competition with each other (competition) for plants from six outcrossing and six selfing populations of $A$. lyrata. Proxies for vegetative performance were (a) belowground biomass and

inbreeding depression for bolting in outcrossing populations $(\delta=0.14$ for plants grown alone), but not in plants from selfing populations $(\delta=-0.02$ for plants grown alone, significant interaction between cross type and mating system; Table 2; Fig. 3a). There was no (b) aboveground biomass in 4-week old plants, and (c) aboveground biomass in 11-week old plants. Error bars are standard errors of the mean of population means. Inbreeding depression values $(\delta)$ are the means of $\delta$ estimates for each population (see Fig. S3)

significant inbreeding depression for inflorescence biomass (no significant effects of cross type or its interactions; Table 2). Competition significantly reduced bolting of plants and inflorescence biomass (significant effect of competition; Table 2), but did not magnify 
Table 2 Linear mixed model analysis to test for inbreeding depression for reproductive potential for six outcrossing and six selfing populations of A. lyrata

\begin{tabular}{|c|c|c|c|c|c|c|}
\hline \multirow[t]{2}{*}{ Explanatory variables (fixed and random effects) } & \multirow[t]{2}{*}{$\mathrm{df}_{\text {num }}$} & \multicolumn{2}{|c|}{$\begin{array}{l}\text { Bolting (Binomial, } \\
n=359 \text { ) }\end{array}$} & \multicolumn{3}{|c|}{$\begin{array}{l}\text { Inflorescence biomass } \\
\left(\text { Gaussian, } \log _{\mathrm{e}}, n=244^{\mathrm{a}}\right)\end{array}$} \\
\hline & & ${ }^{b} \chi^{2}$ & $P$ & ${ }^{c} \mathrm{df}_{\mathrm{den}}$ & $F$ & $P$ \\
\hline \multicolumn{7}{|l|}{ Fixed } \\
\hline Cross type (CT) & 1 & 0.14 & 0.71 & 200.6 & 0.35 & 0.55 \\
\hline Mating system (MS) & 1 & 0.20 & 0.66 & 8.73 & 0.36 & 0.56 \\
\hline Competition (C) & 1 & 10.7 & 0.001 & 196.4 & 15.7 & $<0.001$ \\
\hline CT: MS & 1 & 5.77 & 0.016 & 200.6 & 1.57 & 0.21 \\
\hline CT: C & 1 & 0.038 & 0.85 & 191.4 & 3.25 & 0.073 \\
\hline MS: C & 1 & 1.06 & 0.30 & 196.4 & 1.58 & 0.21 \\
\hline CT:MS:C & 1 & 0.111 & 0.74 & 191.4 & 2.71 & 0.10 \\
\hline Random & \multicolumn{3}{|c|}{ SD } & \multicolumn{3}{|c|}{ SD } \\
\hline Population & 1 & \multicolumn{2}{|c|}{0.571} & \multicolumn{3}{|c|}{0.65} \\
\hline Mother & 1 & \multicolumn{2}{|c|}{0.908} & \multicolumn{3}{|c|}{0.79} \\
\hline Residual & & \multicolumn{2}{|c|}{-} & \multicolumn{2}{|r|}{$\mathrm{df}_{\mathrm{res}}=233$} & \\
\hline
\end{tabular}

Cross type represents inbreeding depression in the model (alone or in interaction with Competition and/or Mating System). Proxies for reproductive performance were bolting (i.e., whether or not plants produced an inflorescence during the experiment) and inflorescence biomass in 11-week old plants. The model error distribution, any applied transformations and sample size are indicated in brackets for each trait. For all traits, the model fixed part included cross type (self vs. cross), mating system (outcrossing vs. selfing) and competition (with vs. without), and all twoway and three-way interactions. The random part included population (nested in mating system) and mother plant (nested in population). Significant values are marked in bold. Significant effects of cross type (as main effect or in interaction) indicate significant inbreeding depression

$d f_{\text {num }}$ : numerator degrees of freedom, $d f_{\text {den }}:$ denominator degrees of freedom

${ }^{a}$ Only for the subset of plants that produced an inflorescence

${ }^{b}$ Wald's $\chi^{2}$ test as implemented in the Anova function in the package car (v3.0-2)

'Significance test based on Satterthwaite's method to adjust $\mathrm{df}_{\mathrm{den}}$, as implemented in the anova function in the package lmerTest (v3.1-0)

Fig. 3 Reproductive potential of crossed- and selfed-progeny grown alone (no competition) or in competition with each other (competition) for plants from six outcrossing and six selfing populations of A. lyrata. Proxies of reproductive potential were (a) bolting (b) inflorescence biomass. All reproductive traits were assessed in 11-week old plants. Error bars are standard errors of the mean of population means. Inbreeding depression values $(\delta)$ are the means of $\delta$ estimates for each population (see Fig. S3)
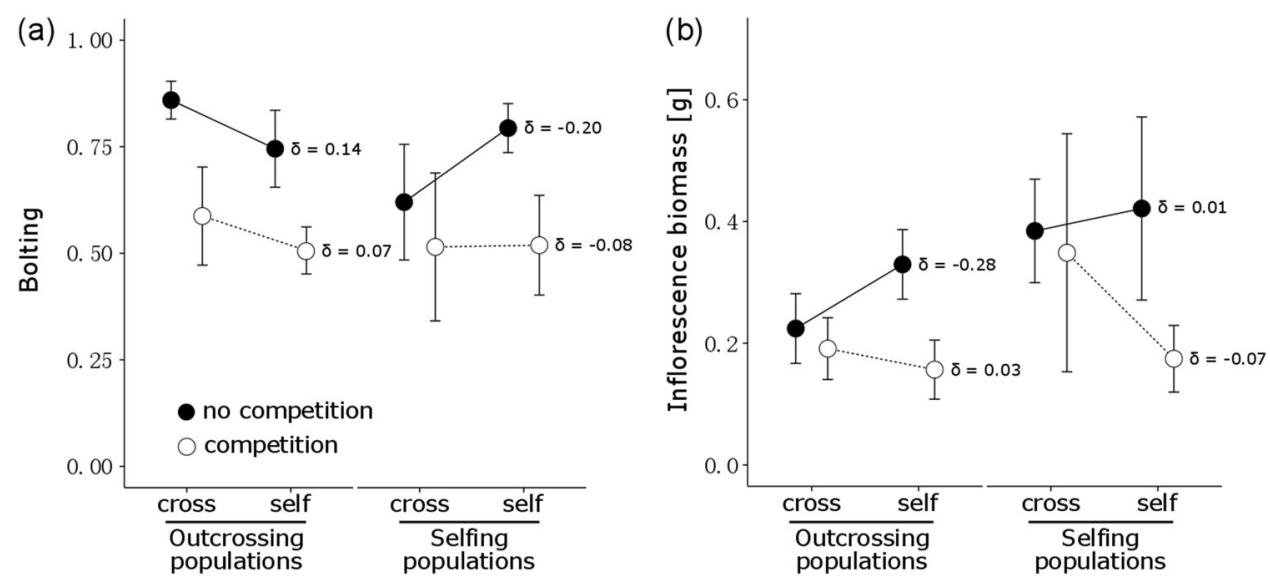

inbreeding depression (no significant interactions of competition with cross type; Table 2). In the subset of plants that had open and spent flowers $(n=154)$, there was no significant inbreeding depression for number of flowers (no significant effects of cross type or its interactions; Table S4), although the two- and three-way interactions with cross type were only marginally nonsignificant (Table S4).

\section{Variation in inbreeding depression between populations}

There was considerable variation in the magnitude of inbreeding depression and the effect of competition among populations (Fig. 4). Although a few population-specific point-estimates exceeded $\delta=0.5$ with competition, the inbreeding estimates were generally well below $\delta=0.5$ and 


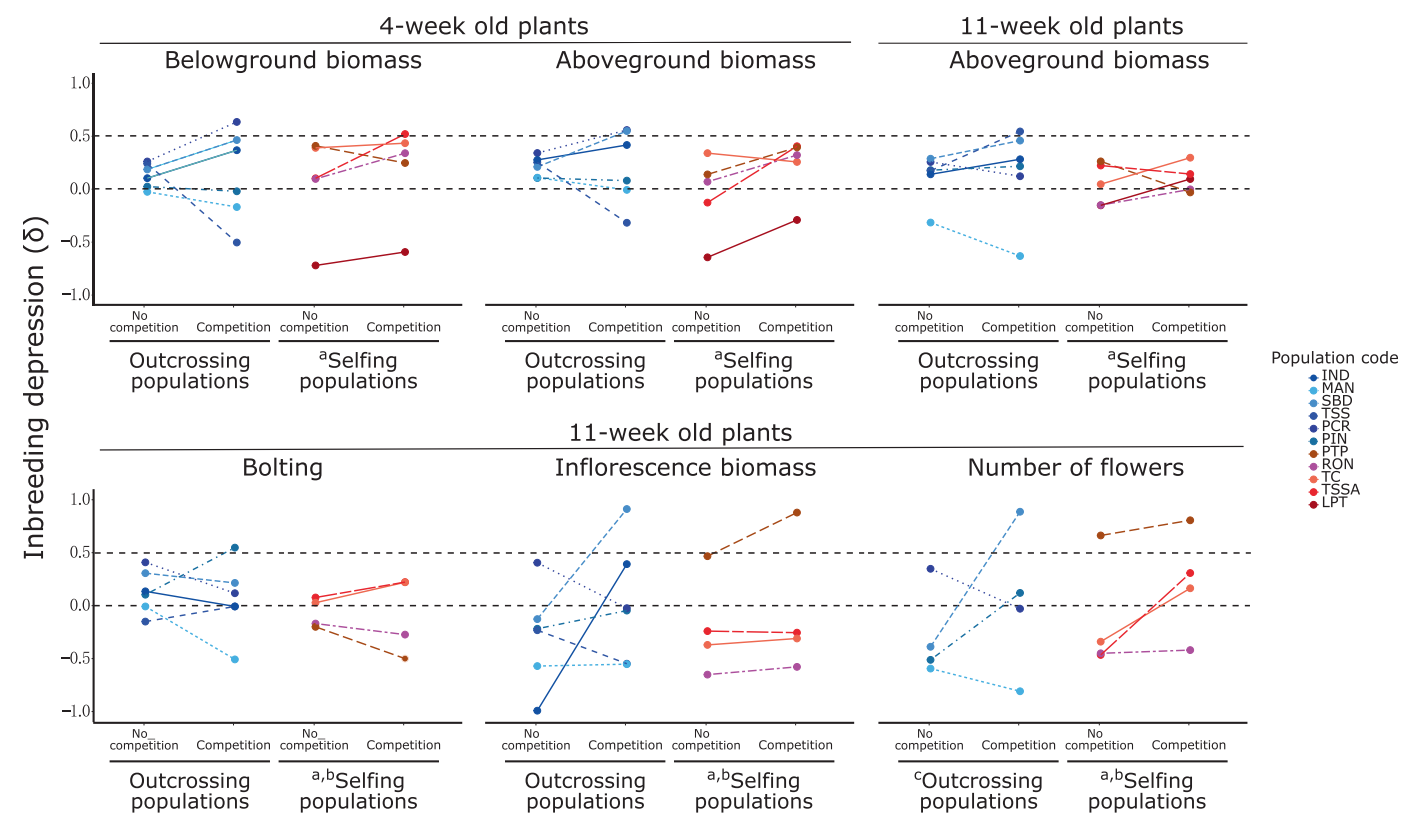

Fig. 4 Inbreeding depression $(\delta)$ without and with sibling competition for outcrossing and selfing populations of A. lyrata for vegetative performance (below- and above-ground biomass of 4-week old plants, and aboveground biomass in 11-week old plants) and reproductive potential (bolting, inflorescence biomass and number of flowers in 11week old plants). For each population, $\delta$ was calculated as $\delta=\left(W_{\text {out }}-\right.$ $\left.W_{\text {self }}\right) / \max \left(W_{\text {out }}, W_{\text {self }}\right)$, in which $W_{\text {out }}$ and $W_{\text {self }}$ are the mean fitness estimates for crossed- and selfed-progeny, respectively. For reference, the dashed lines represent no inbreeding depression $(\delta=0)$ and the theoretical threshold $(\delta=0.5)$ below which the automatic transmission advantage of selfers should drive the evolution of selfing. ${ }^{a}$ None of the

not consistently different between outcrossing and selfing populations.

\section{Discussion}

Our findings show that both selfing and outcrossing populations of North American A. lyrata suffer significant inbreeding depression for biomass and bolting of plants, but not for inflorescence biomass and number of flowers. The magnitude of inbreeding depression did not differ between selfing and outcrossing populations, and was below the critical $\delta=0.5$ threshold for evolution of selfing. Importantly, sibling competition (between crossed- and selfedprogeny) did not significantly change the magnitude of inbreeding depression.

\section{Inbreeding depression in North American populations of $A$. lyrata}

Although direct competition between crossed and selfed siblings had a strong negative effect on plant performance, sibling competition did not magnify inbreeding depression available crossed seeds from KTT germinated (Table S5), so population-specific estimates of inbreeding depression for biomass could only be calculated for five selfing populations; ${ }^{b}$ None of the crossed plants from population LPT had bolted by the end of the experiment (Table S5), so population-specific estimates of inbreeding depression for reproductive traits could only be calculated for four selfing populations; ${ }^{\mathrm{c}}$ None of crossed plants from population IND (no competition) and TSS (competition) flowered in the end of this experiment (Table S5), so population-specific estimates of inbreeding depression for number of flower could only be calculated for four outcrossing populations

in outcrossing and selfing populations of North American $A$. lyrata. This shows that previous estimates of inbreeding depression based on experiments that excluded competition (Carleial et al. 2017; Stift et al. 2013) are not biased downward for that reason. Since drought and inducing defence in a previous study on A. lyrata also did not magnify inbreeding depression (Carleial et al. 2017), our findings suggest that the consistently observed relatively low estimates of inbreeding depression for aboveground biomass (aboveground biomass: $\delta=0.11$ for 4 -week old plants and 0.08 for 11-week old plants, Fig. 2; cumulative vegetative performance $\delta=0.30$ in Carleial et al. 2017) are indeed realistic estimates of the true inbreeding depression in North American A. lyrata. This contrasts with inbreeding-depression estimates for European A. lyrata that were considerably higher (aboveground biomass: $\delta=0.32$; cumulative vegetative performance $\delta=0.51$; Sletvold et al. 2013). Since inbreeding depression represents the only immediate cost of selfing that can offset the transmission advantage of selfers (Kondrashov 1985; Lande and Schemske 1985; Porcher and Lande 2005), these findings may thus help understand why the evolution of selfing could occur in North American A. lyrata. 
The relatively modest magnitude of inbreeding depression likely reflects the evolutionary history of North American A. lyrata subspecies, as multiple lines of evidence suggest that the subspecies has experienced a strong bottleneck (Ross-Ibarra et al. 2008; Mable et al. 2017). Small effective population sizes during such bottlenecks should have led to substantial purging by exposing strongly deleterious recessive mutations to selection (Lynch et al. 1995; Pujol et al. 2009). One would thus expect that inbreeding depression in bottlenecked species, such as North American A. lyrata is predominantly caused by mildly deleterious mutations. As a consequence, additional reductions in effective population size associated with selfing (Busch and Schoen 2008; Wright et al. 2013) are not expected to lead to strong additional purging. This likely explains why North American selfing populations of A. lyrata still suffered from significant inbreeding depression for biomass traits, with little (Carleial et al. 2017) or no evidence (this study) for purging.

\section{Competition and inbreeding depression}

Our experiment revealed no evidence for any interaction of intraspecific competition and inbreeding depression for biomass. Previous work had suggested that the magnitude of inbreeding depression is generally not affected by interspecific competition (Willi et al. 2007), but it had remained unclear whether this also applies to intraspecific competition. As there should be less niche partitioning within species than among species, intraspecific competitive effects should generally be stronger (Barabás et al. 2016; Case 2000), and thus may also aggravate inbreeding depression more strongly. In hindsight, a possible reason why intraspecific competition did not magnify inbreeding depression for biomass could be that our design only forced the plants to compete for belowground resources, but not for light. Belowground competition is usually symmetric, and thus reduces growth of the competing plants proportional to their size (Weiner and Thomas 1986). In other words, under symmetric competition, the size differences between competitors remain stable. Aboveground competition, on the other hand, is usually asymmetric, because the taller individuals overshadow and thereby suppress the growth of the smaller ones, increasing the size differences between the competing plants (Weiner and Thomas 1986). It would therefore be interesting to test whether sibling competition does magnify inbreeding depression if there is increased competition for light.

The absence of an interaction between competition and inbreeding depression may also be related to the pairwise competition inherent to our setup. In the Great Lakes region of eastern North America, A.lyrata occurs in sand dunes, rocky outcrops and alvars (limestone pavements), where plants can occur at relatively high densities of up to 9.4 individuals per $\mathrm{m}^{2}$ (Mable et al. 2005; Mable and Adam 2007). Thus, one would expect density-dependent competition to be important. Moreover, as single plants can produce more than 100 siliques each containing up to 45 without any specific dispersal mechanism, one would expect strong density-dependent competition around mother plants during germination of seedlings. Our experimental setup only forced competition between siblings of different cross types (cross vs. self), but in nature competition within cross type (self vs. self; cross vs. cross) may also be important. In this respect, future studies should consider a setup with varying densities and combinations of crossedand selfed-progeny to more realistically capture the aboveand below-ground competitive interactions that prevail under natural conditions.

Biomass is typically used as a proxy for performance in perennial and self-incompatible plants, such as A. lyrata, (e.g., Løe 2006; Sandring and Ågren 2009). As it is often impossible to harvest all belowground plant parts, biomass estimates are usually for aboveground parts only. We managed to also determine belowground biomass, but only in 4-week old plants, because at that stage it was still possible to separately harvest roots from competing plants. This showed that sibling competition had a strong negative effect on both below- and above-ground biomass (Table 1), confirming that plants were indeed competing. However, both for below- and above-ground biomass (and thus also for total biomass; Fig S1, Table S3) the magnitude of inbreeding depression was independent of competition.

\section{Limited inbreeding depression for reproductive traits}

Biomass is generally a good predictor of lifetimeperformance in self-incompatible species (Løe 2006; Sandring and Ågren 2009). Therefore, one may have expected that our reproductive traits would show similar patterns as biomass. However, this was not the case, as we detected hardly any inbreeding depression for bolting of plants (for plants grown alone, $\delta=0.14$ in outcrossing populations, but $\delta=-0.02$ in selfing populations; Fig. 3, Table 2) and no significant inbreeding depression for inflorescence biomass and number of flowers (Fig. 3, Fig. S2, Table 2, Table S4). Although intuitively closer to "real" fitness, it is important to note that our measures estimate the reproductive potential (not the reproductive output) during the limited time of our experiment. However, in selfincompatible perennial species in which seed set depends on cross-pollination by pollinators, there may only be a very weak correlation between reproductive potential and actual seed set. 


\section{Data archiving}

Data available from the Dryad Digital Repository https:// doi.org/10.5061/dryad.6474895 (Li et al. 2019).

Acknowledgements We thank Samuel Fernandes for help with the crossings, and Claudia Martin, Dominika Kundel, Katya Mamonova, Timo Scheu, Otmar Ficht and Yanjie Liu for help with the experiment. YL was funded by a scholarship from the China Scholarship Council. This project was partly funded by the Deutsche Forschungsgemeinschaft (DFG, German Research Foundation)-project number 388824194 to MS.

\section{Compliance with ethical standards}

Conflict of interest The authors declare that they have no conflict of interest.

Publisher's note Springer Nature remains neutral with regard to jurisdictional claims in published maps and institutional affiliations.

\section{References}

Agrawal AF, Whitlock MC (2010) Environmental duress and epistasis: how does stress affect the strength of selection on new mutations? Trends Ecol Evol 25:450-458

Ågren J, Schemske DW (1993) Outcrossing rate and inbreeding depression in two annual monoecious herbs, Begonia hirsuta and B. semiovata. Evolution 47:125-135

Antonovics J (1968) Evolution of closely adjacent plant populations V. Evolution of self-fertility. Heredity 23:219-238

Barabás G, Michalska-Smith MJ, Allesina S (2016) The effect of intraand interspecific competition on coexistence in multispecies communities. Am Nat 188:E1-E12

Barrett SCH (2002) The evolution of plant sexual diversity. Nat Rev Genet 3:274-284

Bates D, Machler M, Bolker BM, Walker SC (2015) Fitting linear mixed-effects models using lme4. J Stat Softw 67:1-48

Bellanger S, Guillemin JP, Touzeau S, Darmency H (2015) Variation of inbreeding depression in Centaurea cyanus L., a selfincompatible species. Flora 212:24-29

Busch JW, Joly S, Schoen DJ (2010) Does mate limitation in selfincompatible species promote the evolution of selfing? The case of Leavenworthia alabamica. Evolution 64:1657-1670

Busch JW, Delph LF (2012) The relative importance of reproductive assurance and automatic selection as hypotheses for the evolution of self-fertilization. Ann Bot 109:553-562

Busch JW, Schoen DJ (2008) The evolution of self-incompatibility when mates are limiting. Trends Plant Sci 13:128-136

Carleial S, van Kleunen M, Stift M (2017) Small reductions in corolla size and pollen: ovule ratio, but no changes in flower shape in selfing populations of the North American Arabidopsis lyrata. Oecologia 183:401-413

Carr DE, Dudash MR (1995) Inbreeding depression under a competitive regime in Mimulus guttatus: consequences for potential male and female function. Heredity 75:437-445

Case TJ (2000) An illustrated guide to theoretical ecology. Oxford University Press, New York, NY(USA)

Charlesworth D (2006) Evolution of plant breeding systems. Curr Biol 16:R726-R735

Charlesworth D, Charlesworth B (1987) Inbreeding depression and its evolutionary consequences. Annu Rev Ecol Syst 18:237-268
Charlesworth D, Willis JH (2009) The genetics of inbreeding depression. Nat Rev Genet 10:783-796

Cheptou PO, Lepart J, Escarre J (2001) Inbreeding depression under intraspecific competition in a highly outcrossing population of Crepis sancta (Asteraceae): evidence for frequency-dependent variation. Am J Bot 88:1424-1429

Connell JH (1983) On the prevalence and relative importance of interspecific competition: evidence from field experiments. Am Nat 122:661-696

deVillemereuil PB, Lopez-Sepulcre A (2011) Consumer functional responses under intra-and inter-specific interference competition. Ecol Model 222:419-426

Fisher RA (1941) Average excess and average effect of a gene substitution. Ann Eugen 11:53-63

Foxe JP, Stift M, Tedder A, Haudry A, Wright SI, Mable BK (2010) Reconstructing origins of loss of self-incompatibility and selfing in north american Arabidopsis lyrata: a population genetic context. Evolution 64:3495-3510

Koelewijn HP (2004) Sibling competition, size variation and frequency-dependent outcrossing advantage in Plantago coronopus. Evol Ecol 18:51-74

Igic B, Lande R, Kohn JR (2008) Loss of self-incompatibility and its evolutionary consequences. Int J Plant Sci 169:93-104

Kondrashov AS (1985) Deleterious mutations as an evolutionary factor.II. Facultative apomixis and selfing. Genetics 111:635-653

Lande R, Schemske DW (1985) The evolution of self-fertilization and inbreeding depression in plants. I. Genetic models. Evolution 39:24-40

Levin DA (1984) Inbreeding depression and proximity-dependent crossing success in Phlox drummondii. Evolution 38:116-127

Levin DA, Bulinska-Radomska Z (1988) Effects of hybridization and inbreeding on fitness in Phlox. Am J Bot 75:1632-1639

Lhamo N, Ramsey M, Vaughton G (2006) Density- and frequencydependent inbreeding depression in the Australian annual Hibiscus trionum var. vesicarius. Evol Ecol Res 8:717-730

Li Y, van Kleunen M, Stift M (2019) Data from: Sibling competition does not magnify inbreeding depression in North American Arabidopsis lyrata. Dryad Digital Repository. https://doi.org/10. 5061/dryad.6474895

Løe G (2006). Ecology and evolution of resistance to herbivory: trichome production in Arabidopsis lyrata. Acta Univ. Ups.

Lynch M, Conery J, Burger R (1995) Mutational meltdowns in sexual populations. Evolution 49:1067-1080

Mable BK, Robertson AV, Dart S, Di Berardo C, Witham L (2005) Breakdown of self-incompatibility in the perennial Arabidopsis lyrata (Brassicaceae) and its genetic consequences. Evolution 59:1437-1448

Mable BK, Adam A (2007) Patterns of genetic diversity in outcrossing and selfing populations of Arabidopsis lyrata. Mol Ecol $16: 3565-3580$

Mable BK, Hagmann J, Kim S, Adam A, Kilbride E, Weigel D et al. (2017) What causes mating system shifts in plants? Arabidopsis lyrata as a case study. Heredity 118:52

Nakanishii T, Esashi Y, Hinata K (1969) Control of selfincompatibility by $\mathrm{CO}_{2}$ gas in Brassica. Plant Cell Physiol 10:925-927

Porcher E, Lande R (2005) The evolution of self-fertilization and inbreeding depression under pollen discounting and pollen limitation. J Evolution Biol 18:497-508

Pujol B, Zhou SR, Vilas JS, Pannell JR (2009) Reduced inbreeding depression after species range expansion. Proc Natl Acad Sci USA 106:15379-15383

R Core Team (2017) R: A language and environment for statistical computing. R Foundation for Statistical Computing, Vienna, Austria

Ross-Ibarra J, Wright SI, Foxe JP, Kawabe A, DeRose-Wilson L, Gos G et al. (2008) Patterns of polymorphism and 
demographic history in natural populations of Arabidopsis lyrata. Plos ONE 3:10.1371

Sandring S, Ågren J (2009) Pollinator-mediated selection on floral display and flowering time in the perennial herb Arabidopsis lyrata. Evolution 63:1292-1300

Schoener TW (1973) Population growth regulated by intraspecific competition for energy or time: some simple representations. Theor Popul Biol 4:56-84

Shimizu KK, Tsuchimatsu T (2015) Evolution of selfing: recurrent patterns in molecular adaptation. Annu Rev Ecol Evol Syst 46:593-622

Sletvold N, Mousset M, Hagenblad J, Hansson B, Agren J (2013) Strong inbreeding depression in two scandinavian populations of the self-incompatible perennial herb Arabidopsis lyrata. Evolution 67:2876-2888

Stift M, Hunter BD, Shaw B, Adam A, Hoebe PN, Mable BK (2013) Inbreeding depression in self-incompatible North-American Arabidopsis lyrata: disentangling genomic and S-locus-specific genetic load. Heredity 110:19-28
Stone JL, VanWyk EJ, Hale JR (2014) Transmission advantage favors selfing allele in experimental populations of self-incompatible Witheringia solanacea (Solanaceae). Evolution 68:1845-1855

Tsukamoto T, Ando T, Takahashi K, Omori T, Watanabe H, Kokubun H, Marchesi E, Kao T-h (2003) Breakdown of selfincompatibility in a natural population of Petunia axillaris caused by loss of pollen function. Plant Physiol 131:1903-1912

Vogler DW, Filmore K, Stephenson AG (2001) Inbreeding depression in Campanula rapunculoides L. I. A comparison of inbreeding depression in plants derived from strong and weak selfincompatibility phenotypes. J Evolution Biol 12:483-494

Weiner J, Thomas SC (1986) Size variability and competition in plant monocultures. Oikos 47:211-222

Willi Y, Dietrich S, van Kleunen M, Fischer M (2007) Inter-specific competitive stress does not affect the magnitude of inbreeding depression. Evol Ecol Res 9:959-974

Wright SI, Kalisz S, Slotte T (2013) Evolutionary consequences of self-fertilization in plants. Proc R Soc Lond B Bio 280:20130133 